\title{
Modern contraceptive use among women in Uganda: An analysis of trend and patterns (1995-20II)
}

\author{
Jimmy Ronald Andi ${ }^{1}$, Robert Wamala ${ }^{2}$, Bruno Ocaya ${ }^{3}$ and Allen Kabagenyi ${ }^{4}$ \\ ${ }^{1234}$ Makerere University, Uganda
}

\begin{abstract}
There is an extensive body of literature concerning modern contraceptive use among women in Uganda. A questionable aspect however is whether the impact of factors associated with modern contraceptive use has remained the same in the recent past. Demographic Health Survey (DHS) data of women in the period 1995-20II was adopted to establish an understanding of this issue. The focus in the investigations was none pregnant sexually active women. Variations in patterns of modern contraceptive use were assessed by socioeconomic and demographic characteristics of women using a logistic regression based on a complex survey design. In the results, an upward trend in modern contraceptive use - from $11.6 \%$ in 1995 to $32.1 \%$ in 2011 - shows that progress has been made in this regard. Increased odds of modern contraceptive use across the study period were noted among women with primary and post-primary education, those in urban areas, women in the higher wealth quartiles and those with a higher number of surviving children $(p<0.01)$. Further, reduced odds of modern contraceptive use across the study period were noted among married women and those in cohabiting relationships $(p<0.05)$. The study however demonstrates variations in the impact of these factors across the study period. All the same, efforts towards enhancing modern contraceptive use in the near future should focus on enhancing: (i) literacy levels of woman particularly, (ii) access to and affordability of the services, and (iii) awareness campaigns on family planning use targeting both men and women.
\end{abstract}

Keywords: Family planning utilization; modern contraceptive use; Uganda

\section{Résumé}

II existe un corpus scientifique important sur l'utilisation de méthodes contraceptives chez les femmes en Ouganda. L'un des aspects à réexaminer concerne l'impact des facteurs associés à l'utilisation de méthodes de contraception moderne pour savoir s'il est resté identique dans un passé récent. Les données sur les femmes du Demographic Health Survey (DHS) sur la période 1995-20l lont été choisies pour parvenir à comprendre cette question. Ces analyses ont pris pour objet les femmes non enceintes et sexuellement actives. Les variations dans les modes d'utilisation de méthodes contraceptives modernes sont étudiées au travers de caractéristiques socio-économiques et démographiques des femmes avec des régressions fondées sur des modèles complexes. Les résultats trouvés montrent une tendance à l'augmentation dans l'utilisation de méthodes contraceptives de $I I, 6 \%$ en 1995 à 32,I\% en $20 I I$, démontrant le progrès réalisé en la matière. L'augmentation des chances d'utilisation des méthodes modernes de contraception durant la période étudiée a été constatée chez les femmes ayant reçu une éducation primaire et au-delà, celles qui se trouvent en milieu urbains, celles qui sont dans les quartiles de richesse les plus élevés et celles qui ont le plus grand nombre d'enfants survivants $(p<0,01)$. De plus des chances plus réduites d'utilisation de contraceptifs modernes durant la période étudiée ont été notées parmi les femmes mariées et celles en cohabitation $(p<0,05)$. Cette étude démontre cependant les variations de l'impact de ces facteurs durant la période étudiée. Malgré cela les efforts de promotion des méthodes d'utilisation de contraceptifs modernes dans le futur proche devrait s'efforcer de promouvoir: (i) les niveaux d'éducation des femmes tout particulièrement, (ii) l'accès à des services peu couteux et enfin (iii) des campagnes de sensibilisation sur l'utilisation de méthodes de planification familiale visant à la fois les hommes et les femmes.

Mots clé: utilisation de méthodes de planification familiale; moyens de contraception modern; Ouganda 


\section{Introduction}

Family planning (FP) is defined by the World Health Organization (WHO) as a voluntary and informed decision by an individual or couple on the number of children to have and when to have them. According to the 2013 WHO fact sheet on FP, "it is achieved mainly through use of various contraceptive methods and treatment of involuntary infertility" (WHO, 2013, p.I). Among the major benefits of a woman's ability to space and limit pregnancies comprise: a direct impact on their health and wellbeing as well as outcome of pregnancies (WHO, 20I2; 2013).

Contraceptive methods can be categorized by two major groups namely, modern and traditional methods. Modern contraceptive methods comprise female sterilization, male sterilization, pills, Depot Implants, male condoms, female condoms, Intra Uterine Devices (IUD), Lactational Amenorrhea Method (LAM) and emergency contraception (WHO, 2008; 2013). On the other hand, traditional methods comprise rhyme method (periodic abstinence) and withdrawal. Although the WHO considers all these methods to be safe for all persons, the effectiveness of the latter group is questionable. Globally, modern contraceptive utilization has increased in the recent past - from $54 \%$ in 1990 to $57 \%$ in 2012 (WHO, 20I2). However, the estimates in Africa remain persistently low at $23 \%$ and $24 \%$, respectively. The estimates among countries in the Sub-Saharan region are much lower than the aforementioned figures. This has been attributed - among other factors - to shortfalls in health infrastructure and transport facilities (Cleland, et al., 2006; UNFPA, 20I2). Further, these studies show that women tend to seek long lasting family planning methods such as intrauterine devices, Injectable and implants which are often not readily available. Thus, a $2013 \mathrm{WHO}$ study revealing an estimated 222 million women in developing countries who want to space or prevent child bearing but lack access to modern contraceptive methods would not be surprising. This situation normally results in high fertility which in turn is associated with high levels of maternal mortality especially among the poorest women (Cleland, et al., 2006; UNFPA, 2012).

According to Uganda Bureau of Statistics (UBOS), FP services were introduced in the country in the 1950's with the establishment of Family Planning Association of Uganda. In 1995, the country adopted the National Population Policy (NPP) whose overall goal was to influence future demographic trends and patterns in a desirable direction in order to improve quality of life and standards of living of her people (UBOS and Macro International, 1995). The NPP was to increase contraceptive prevalence rate from $7.8 \%$ to $15 \%$ by 2000 (Population Secretariat, 1995, p.28). Despite the goal of doubling the contraceptive prevalence by the 2000 target date, the figures are low when compared to the estimates in the developed countries. Low contraceptive use has been highlighted as one of the key contributing factors to the high maternal mortality rate in the country estimated at 438 deaths per 100,000 (UBOS and ICF International, 20II). In comparison to the country's estimate of 527 deaths per 100,000 in 1995 (UBOS and Macro International, 1995), there has been a reduction in maternal mortality in the recent past. However, the country's estimates do not compare favorably with global average of 287 (WHO, 20I2) and more so the Millennium Development Goal (MDG) target of 230 deaths per 100,000 by the 2015 target date.

According to the 201I Uganda Demographic Health Survey (UDHS), the country's contraceptive uptake (any method) is estimated at $30 \%$ (UBOS and ICF International, 20I I). This figure has doubled over a span of sixteen years - the contraceptive uptake in 1995 was about $15 \%$ (UBOS and Macro International, 1995). The country's contraceptive prevalence rate is lower than figures among neighboring countries namely Kenya (46\%), Tanzania (34\%) and Rwanda (52\%) (ICF International, 20I2). With regards to the use of modern contraceptive methods, the country lags behind in comparison with the global estimates and those among the neighboring countries. According to 201I UDHS, the use of modern contraceptive methods in the country has increased when compared to the 2000/200 I estimates of 14\% (UBOS and Macro International, 2000/200I). Nevertheless, the estimates point to a low utilization of modern contraceptives in the country. This situation certainly contributes to the increase in the number of unwanted pregnancies (UBOS and Macro International, 2006). In addition, the high unmet need for family planning in the country (34\%) worsens the issue of unwanted pregnancies particularly among the adolescents. To this end, a high fertility rate of 6.2 children per woman (UBOS and ICF International, 20II) would not be surprising. As a matter of fact, the country has been cited to have one of the highest total fertility rates 
worldwide (Hladik, et al., 2009). This evidence points to an increasing population of the country which is certainly constrained by resources among other aspects. The increasing population posses a great challenge to economic development of the country given the scarce resources. It is on this basis that the government emphasizes the use of family planning services to reduce population growth (MoH, 2005). However, the dearth of documented evidence on patterns of modern contraceptive use in the recent past hampers efforts towards enhancing their utilization in the subsequent period. Recent studies on contraceptive use both locally (Agyei and Epema, 1990; DeRose, et al., 2010; Ntozi and Kabera, 1991; Thomas et al., 2000) and internationally (Lanre, 201 I; McGinn, et al., 201 I; Najafi, et al., 2012; Rob, et al., 2007) provide an assessment of contraceptive use at various points in time. Although the studies provide a basis for obtaining an understanding of FP utilization in the country, it is questionable whether the impact of factors associated with the utilization of modern contraceptives has remained the same in the recent past. In other words evidence from 1995 demographic health study on contraceptive use cannot be applied entirely to women in 2000/200I, 2006 and $201 \mathrm{I}$. This situation hampers future efforts towards enhancing family planning utilization in the country. This study therefore sought to address the aforementioned shortfalls by providing an assessment of trend and patterns of modern contraceptive use among women in the country.

\section{Literature Review and Theoretical Framework}

The concept of FP utilization adopted in the study is based mainly on Anderson's 1995 model of health care utilization. The model presents health service utilization as an aspect of predisposing, enabling and need factor. The socio-economic and demographic characteristics of the women, denoted as predisposing factors in Anderson's model, are considered to be the factors for FP utilization. The enabling factors in Anderson's model comprise family support, access to health insurance and one's community. However, some of these factors are outside the scope of the study. All the same, residence and religion could be used as a proxy for assessing the enabling factors. Figure I presents a conceptual framework adopted in guiding the study. The framework shows the path through which the socio-economic and demographic characteristics of the women operate to influence modern contraceptive use.

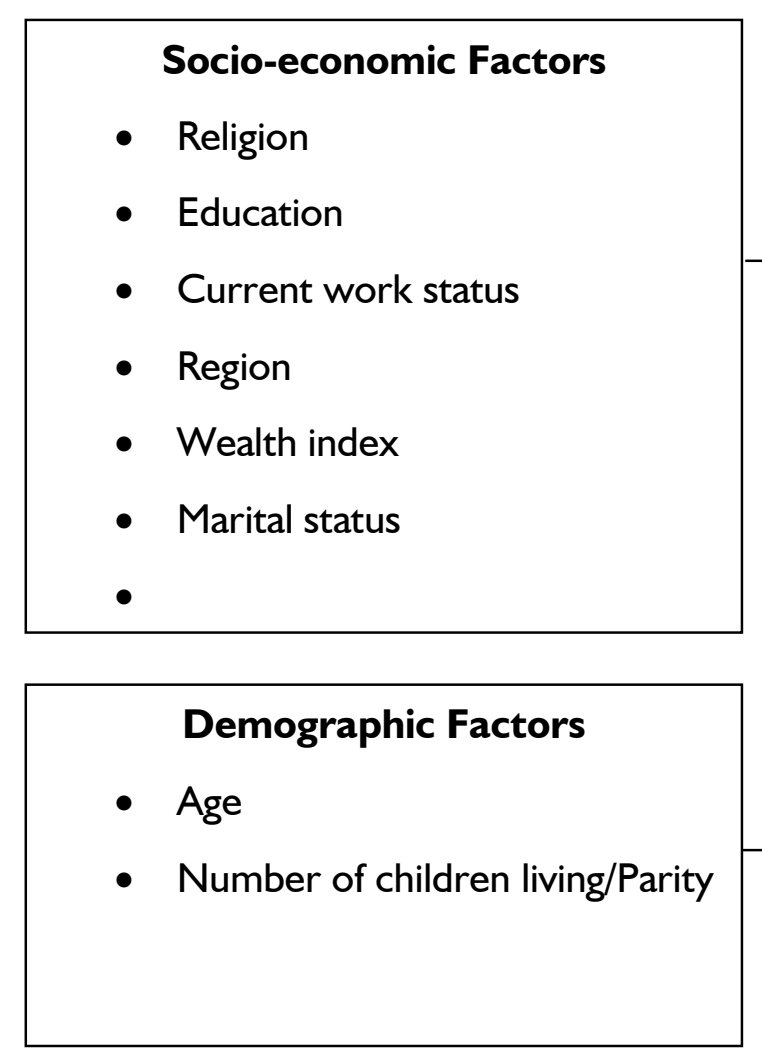

Figure I: Diagrammatic representation of factors associated with modern contraceptive use

The socio-economic and demographic characteristics of women are suggested to impact directly on modern contraceptive use. The issue of 1011 contention is whether the impact of these factors on modern contraceptive use has been the same across the study period. In any case, the influence of these http://aps.journals.ac.za 
factors on modern contraceptive use is supported by studies in Uganda and elsewhere. A review of relevant literature on each of these factors is made subsequently.

Worldwide, religion has played a leading role in discouraging dissemination of information on FP use. Particularly, Catholics have a restriction in matters concerning contraceptive use (e.g., Gupta and Leite, 1999; Lanre, 201 I). Their teaching discourages the use of modern contraceptives on grounds that unnatural methods encourage promiscuity (e.g., Ntozi, et al., 2000; Ntozi, 1998). In countries that are predominantly Catholic (for example Brazil), the Catholic church is at the forefront of influencing government policies particularly in the area of limiting FP services available and discouraging fertility limiting behaviors (Gupta and Leite, 1999). However, there is no consensus regarding the use of contraception among the Muslims although conservative Islamic leaders have openly campaigned against the use of condoms and other birth control methods (Dawud, 2008). Nevertheless, the influence of religion has stiffened the transmission of adequate and accessible information via radios and televisions as well as in schools (Coliver, 1995).

With regards to residence, Bongaats and Potter (1983) noted that contraceptive prevalence is higher among women in the urban areas. This evidence is supported by studies in Uganda (UBOS and Macro International, 2006) and elsewhere (Obung, Cross and Njogu, 1991; Gardner, et al., 1999; Nguyen, et al., 2002). This is because FP clinics are in most cases located in urban areas; this affects accessibility of the services among the rural women. In affirming to the variation in FP use by rural-urban residence, the 2006 DHS noted that the use of FP is more than twice as high in urban areas when compared to the rural (UBOS and Macro International, 2006). It is therefore no surprise that contraceptive use is higher in the northern region of Uganda which is predominantly rural when compared to the central region which is mainly urban. Likewise, a higher contraceptive use among educated women (Hagen, et al., 1999; Kravdal, 2002; Lutalo, et al., 2000; Rob, et al., 2007; Rutenburg, et al., I99।; Utomo, et al., 1983; UBOS and Macro International, 2006) would not be surprising. This is because educated women are more likely to be located in the urban areas than in the rural. In a study regarding contextual influences on modern contraceptive use among women in six Sub-Saharan African countries, Rob et al. (2007), noted that secondary or higher

http://aps.journals.ac.za educational attainment was more likely to be associated with use of modern contraceptives.

The fact that modern contraceptive methods have cost implications, the wealth status of woman play an important role in enhancing FP utilization. Imposing or raising fees of contraceptive methods deters poor people from using the services (Creanga, et al., 20II; Bailey, et al., 1994; Lewis, 1986). In the event that formal fees on contraceptives are low or non-existent, these study reveals that other costs associated with the services and related aspects (for example, transport) could hinder women from seeking contraceptive services. A study of adolescents in Uganda does not reveal otherwise on this issue (Wangei, et al., 200I). Particularly, a study of wealth status and family planning reveals that modern contraceptive use is more than twice as high among the wealthiest women when compared to the poorest women (Family Health Initiative, 2010).

Pertaining to marital status, the argument is that married people highly depend on their spouses for approval of modern contraceptive use. In the contrary, the non-married women do not usually seek approval from any one in matters concerning contraceptive use. Thus, husband's non approval was cited as the major reason for non use of modern contraceptive among the married women (UNFPA, 199I). According to the 2004 population report, it was argued that women who know their husbands' attitude towards contraception were more likely to use modern contraceptive methods when compared to those who were not aware. Thus, the low utilization of modern contraceptive services among married women in many developing countries would not be surprising. On the same note, women in male headed households are regarded to have reduced odds of modern contraceptive use when compared to their counterparts in female headed households (Wener, 1983; Sembajwe and Makatjane, 1987).

In the study on contextual influences on modern contraceptive use among women in Kenya, Malawi, Tanzania, Ivory Cost, Burkina Faso, and Ghana, Rob et al.(2007) noted that women in the younger ages (especially the age group 20-29) were more likely to use modern contraceptive methods. These findings are supported by studies carried-out in the early 1980s (e.g., Bongaarts and Potter, 1983). Their study noted that age specific contraceptive prevalence rate increase with age of women until a maximum is reached in the age group $30-34$ and declines at older ages. With regards to parity, the 
consensus is that contraceptive use is more likely among women with higher number of surviving children (Agyei and Migadde, 1995; Rutenburg, et al., 1991; Thomas et al., 2000). Also, many women reject contraception because bearing and raising children is the path to respect and dignity (Cherkaoui, 2000; Barnett and stein, 200I).

Although the discussions made in the aforementioned sections provide a background for understanding contraceptive use in Uganda and elsewhere, they cannot be used as a basis for assessing variations in patterns of contraceptive utilization across the study period. In other words, the pattern of modern contraceptive use in 1990s may not be entirely applied to the situation in recent past.

\section{Data and methods}

\section{Data source}

The investigations were based on Uganda Demographic and Health Survey (UDHS) data for the years 1995, 2000/200I, 2006 and 20II. Nationally representative samples of households considered in the surveys were obtained using a two-stage cluster sampling (UBOS and Macro International, 1995; 2000/200I; 2006; UBOS and ICF International, 20I I). The first stage involved the selection of the clusters while the second stage selected the households in each cluster. Stratification of urban and rural areas was taken into account. Although the UDHS for the respective periods were based on four data collection instruments, the investigations in this study were made using data compiled from the women's questionnaire. Table I presents details regarding the number of Primary Sampling Units (PSU), number of districts reached and sample sizes (n) adopted across the study period. The PSU represents Enumeration Areas (EA); which were considered in the study to be urban-rural variations in geographical locations.

Table I: Summary of sampling adopted across the study period

\begin{tabular}{|l|l|l|l|l|}
\hline Year & PSU & Districts & n & Sample $^{\text {a }}$ \\
\hline 1995 & 295 & 38 & 7070 & 4256 \\
\hline $2000 / 2001$ & 298 & 42 & 7246 & 4679 \\
\hline 2006 & 404 & 56 & 8531 & 5246 \\
\hline 2011 & 405 & 112 & 8674 & 5218 \\
\hline
\end{tabular}

Note: the PSUs represent the EA

${ }^{\text {a }}$ Represents none pregnant women who were sexually active

The data adopted in the investigations represents non-pregnant women (15-49) who were sexually active at the time of the survey. Women who had sexual intercourse in the past one year prior to the survey were regarded to be sexually active.

\section{Variables and their Measurements}

The status of modern contraceptive use - the outcome variable - was modeled using a binary outcome i.e. whether or not a woman was using modern contraceptives. Women who were either using a traditional method or not using any other contraceptive methods at the time of the study were regarded as not using modern methods. The independent variables were women's demographic (age and number of surviving children) and socioeconomic (educational level, residence, religion, marital status, current work status, socio-economic status assessed using the wealth index and geographical region of residence) characteristics. Data pertaining to the wealth index was however not available in the years 1995 and 2000/200I.

\section{Data Analysis}

Prior to the analysis, the data were weighted to: (i) ensure representativeness across the country, (ii) correct for non-responses stratified by regions and residence. The sample weight denotes an eight-digit variable with six implied decimal places. Before applying the weighting factor, the sample weight was divided by $1,000,000$ (UBOS and ICF International, 2011; UBOS and Macro International, 1995; 2000/200I; 2006). All the sample weights were normalized to ensure that the weighted number of cases is identical to the un-weighted number when using the full data set with no selection.

The analysis was carried out at two stages: First, an assessment of variations in socio-economic and demographic characteristics of women by the year of study was made using cross-tabular analysis and associations investigated using the Pearson Chisquare test. Second, a multiple logistic regression based on a complex survey design was adopted in investigating the predictors of modern contraceptive use across the study period. Choice of the approach was based on the fact that the dependent variable 
was modeled using a binary nominal outcome. The likelihood of modern contraceptive use was investigated by socio-economic and demographic characteristics of women using a logistic regression based on the computational formulae:

$$
\ln \left[\frac{\mathrm{p}_{\mathrm{i}}}{1-\mathrm{p}_{\mathrm{i}}}\right]=\beta_{\mathrm{o}}+\beta_{1} \mathrm{X}_{1}+\ldots+\beta_{\mathrm{k}} \mathrm{X}_{\mathrm{k}}
$$

Where $p_{i}$ represents the probability of using modern contraceptive methods; ${ }^{1-} \mathrm{p}_{\mathrm{i}}$ represents the probability of not using the methods; $X_{i}$ and $\beta_{1}$ represents the independent variables and their corresponding coefficients while $\beta_{0}$ is the constant. The survey logistic regression models were investigated for appropriateness using Archer Lemeshow goodness of fit test (Hosmer and Lemeshow, 1980).

\section{Assessment of patterns of modern contraceptive use}

The assessment in the patterns of modern contraceptive use across the study period was based on probability values ( $\mathrm{p}$-value) and confidence intervals of the estimates made on the independent variables. The comparisons were made as follows:
I. Variables that were significant predictors of modern contraceptive use across the study period $(p<0.05)$ were considered as consistent predictors of modern contraceptive use.

(1)

2. Variations in the consistent predictors of modern contraceptive use were assessed using confidence intervals obtained in the regression analysis. If an estimate in one period falls in the confidence interval of the next period, then the impact of a variable is considered not to be significantly different.

\section{Results}

The analysis in the subsequent sections is made on characteristics of women, status of modern contraceptive use and predictors of modern contraceptive use across the study period. As earlier stated, estimates at the various stages of the analysis are obtained based on complex survey design.

\section{Characteristics of women}

Table 2 presents a cross-tabular analysis of the socio-economic and demographic characteristics of women across the study period; a summary of the results made subsequently. 
Table 2: Distribution of socio-economic and demographic characteristics of women

\begin{tabular}{|c|c|c|c|c|}
\hline \multirow[t]{2}{*}{ Characteristics } & \multicolumn{4}{|c|}{ Year of Study (\%) } \\
\hline & 1995 & $2000 / 200 I$ & 2006 & 2011 \\
\hline \multicolumn{5}{|l|}{ Religion } \\
\hline Catholics & 44.3 & 41.5 & 45.2 & 40.8 \\
\hline Muslims & 11.7 & 13.5 & 12.3 & 14.2 \\
\hline Protestants & 39.9 & 39.3 & 35.1 & 29.8 \\
\hline Others & 4.1 & 5.8 & 7.4 & 15.3 \\
\hline Total & 100.0 & 100.0 & 100.0 & 100.0 \\
\hline \multicolumn{5}{|l|}{ Educational level } \\
\hline No education & 32.6 & 23.6 & 21.7 & 14.1 \\
\hline Primary & 55.5 & 59.4 & 58.2 & 59.0 \\
\hline Post-primary & 11.9 & 17.0 & 20.1 & 26.9 \\
\hline Total & 100.0 & 100.0 & 100.0 & 100.0 \\
\hline \multicolumn{5}{|l|}{ Age } \\
\hline $15-19$ & 14.8 & 12.7 & 10.6 & 10.8 \\
\hline $20-29$ & 43.5 & 43.8 & 40.9 & 42.7 \\
\hline $30-39$ & 28.1 & 28.4 & 30.9 & 29.2 \\
\hline $40-49$ & 13.6 & 15.1 & 17.7 & 17.3 \\
\hline Total & 100.0 & 100.0 & 100.0 & 100.0 \\
\hline \multicolumn{5}{|l|}{ Children Alive } \\
\hline none & 13.5 & 12.1 & 10.9 & 11.3 \\
\hline I -2 & 34.1 & 30.9 & 28.8 & 27.5 \\
\hline $3-4$ & 23.1 & 27.0 & 25.1 & 26.0 \\
\hline 5 and above & 29.3 & 30.0 & 35.2 & 35.3 \\
\hline Total & 100.0 & 100.0 & 100.0 & 100.0 \\
\hline \multicolumn{5}{|l|}{ Residence } \\
\hline Rural & 85.6 & 83.6 & 82.9 & 79.8 \\
\hline Urban & 14.4 & 16.4 & 17.1 & 20.2 \\
\hline Total & 100.0 & 100.0 & 100.0 & 100.0 \\
\hline \multicolumn{5}{|l|}{ Marital status } \\
\hline Single & 5.7 & 8.2 & 9.1 & 9.5 \\
\hline Married & 78.1 & 55.9 & 63.3 & 46.2 \\
\hline Cohabiting & 12.0 & 27.3 & 17.6 & 34.8 \\
\hline Separated/Divorced & 4.2 & 8.6 & 10.1 & 8.9 \\
\hline Total & 100.0 & 100.0 & 100.0 & 100.0 \\
\hline \multicolumn{5}{|l|}{ Wealth quintile } \\
\hline Lowest & . & . & 17.5 & 16.6 \\
\hline Second & . & . & 19.3 & 18.0 \\
\hline Middle & . & . & 19.6 & 19.5 \\
\hline Fourth & . & . & 19.1 & 19.9 \\
\hline Highest & . & . & 24.6 & 26.1 \\
\hline Total & . & . & 100.0 & 100.0 \\
\hline \multicolumn{5}{|l|}{ Work status } \\
\hline Not working & 37.6 & 22.8 & 14.1 & 26.1 \\
\hline Working & 62.4 & 77.2 & 85.9 & 73.9 \\
\hline Total & 100.0 & 100.0 & 100.0 & 100.0 \\
\hline \multicolumn{5}{|l|}{ Region } \\
\hline Central & 26.7 & 32.6 & 28.7 & 33.2 \\
\hline Eastern & 25.6 & 28.1 & 23.2 & 25.9 \\
\hline Western & 28.0 & 23.5 & 27.6 & 26.5 \\
\hline Northern & 19.7 & 15.8 & 20.5 & 14.4 \\
\hline Total & 100.0 & 100.0 & 100.0 & 100.0 \\
\hline
\end{tabular}

Note: Dashes (.) denote missing data - variable not available in a year

According to results in Table 2, the highest proportions of women across the study period were Christians i.e. Catholics and Protestants. Worth 1015 noting is a steady rise in the proportion of women belonging to other religious affiliations - the proportion increased significantly from $4.1 \%$ in 1995 
to $15.3 \%$ in $20 \mathrm{II}$. With regards to education level, the highest proportion of the women across the study period had primary as their highest level of education attained. Further, the results reveal a steady rise in the proportion of women with postprimary education in the study period from $11.9 \%$ in $1995,17.0 \%$ in $2000 / 2001,20.1 \%$ in 2006 to $26.9 \%$ in $201 \mathrm{I}$. On the contrary, a decrease in the proportion of women with no formal education across the study period was noted from $32.6 \%$ in 1995 to $14.1 \%$ in 2011.

Pertaining to residence, majority of the women across the study period were residing in rural areas. Worth noting is an upward trend in the proportion of women residing in urban areas from $14.4 \%$ in 1995 to $20.2 \%$ in $201 \mathrm{I}$. With regards to regional coverage, the largest proportion across the study period was women from the central and western region; the least proportion was women from the northern region.

The highest and lowest proportion of women was in the highest and lowest groups with regards to wealth quartiles, respectively. In any case, a similar pattern regarding the distribution of women by wealth quartile is noted in 2006 and 201 I. Similarly, majority of women across the study period were employed. However, upward tread in the proportion of women who were employed was noted in the period $1995-2006$. The 201 I estimate
(73.9\%) demonstrates a reduction in proportion of employed women when compared to the figure in 2006 (85.9\%). With regards to marital status, the largest proportions of women across the study period were married followed by the cohabiting group while the rest were either single or divorced/separated/widowed. Worth noting is a steady rise in the proportion of the cohabiting group in the study period - the estimates are $12.0 \%$, $27.3 \%, 17.6 \%$ and $34.8 \%$ in $1995,2000 / 2001,2006$ and $201 \mathrm{I}$, respectively.

Regarding the demographic characteristics, the highest proportions across the study period were in their $20 \mathrm{~s}$ and $30 \mathrm{~s}$ with regards to age. The lowest proportions across the study period were women below 20 years and those in their 40s with regards to age. Worth noting is that the proportion of women in latter group increased steadily from $13.6 \%$ in $1995,15.1 \%$ in $2000 / 2001,17.7 \%$ in 2006 to $17.3 \%$ in 2011 . On the other hand, the largest proportions of women across the study period were those with at-least five children with the exception of women in 1995. However, no major variation in the distribution of women with regards to parity was noted across the study period.

\section{Modern contraceptive use}

Table 3 presents distribution of women with regards to their status of modern contraceptive use across the study period.

Table 3: Status of modern contraceptive use across study period

\begin{tabular}{|c|c|c|c|c|}
\hline \multirow{2}{*}{$\begin{array}{l}\text { Modern } \\
\text { contraceptive use }\end{array}$} & \multicolumn{4}{|c|}{ Year of Study (\%) } \\
\hline & 1995 & $2000 / 200 I$ & 2006 & 2011 \\
\hline Yes & 11.6 & 24.3 & 24.2 & 32.1 \\
\hline No & 88.4 & 75.7 & 75.8 & 67.9 \\
\hline Total & 100.0 & 100.0 & 100.0 & 100.0 \\
\hline
\end{tabular}

Result in Table 3 shows an upward trend in the proportion of women using modern contraceptive methods. Although the largest proportion of women was not using modern contraceptive methods across the study period, the proportion of those using almost tripled in 2011 (32.1\%) when compared to the figure in 1995 (11.6\%). Certainly, progress has been made in enhancing access to and utilization of family planning services in general and modern contraceptives particularly (WHO, 2013; UBOS and ICF Macro, 20 I ; ICF International, 20I2).

\section{Predictors of modern contraceptive use}

Table 4 presents likelihood estimates of modern contraceptive use. The assessment was made using a multiple logistic regression based on a complex survey design. The analysis was made on UDHS data in the years 1995, 2000/200I, 2006 and 201I. A summary of the findings is made subsequently. 
Table 4: Regression estimates of modern contraceptive use across study period

\begin{tabular}{|c|c|c|c|c|}
\hline \multirow[t]{2}{*}{ Characteristics } & \multicolumn{4}{|c|}{ Year of Study (Odds Ratio: $95 \% \mathrm{Cl}$ ) } \\
\hline & 1995 & $2000 / 2001$ & 2006 & 2011 \\
\hline \multicolumn{5}{|l|}{ Religion } \\
\hline Catholics $^{\dagger}$ & 1.00 & 1.00 & 1.00 & 1.00 \\
\hline Muslims & $\mathrm{I} .35(0.7 \mathrm{I}-2.57)$ & $0.95(0.65-1.39)$ & $1.20(0.88-1.64)$ & $0.88(0.71-1.10)$ \\
\hline Protestants & $\mathrm{I} .22(0.63-2.36)$ & $0.8 I(0.56-1.16)$ & $1.35(0.99-1.84)$ & $1.02(0.86-1.22)$ \\
\hline Others & $\mathrm{I} .70(0.84-3.45)$ & $1.06(0.70-1.61)$ & $1.25(0.87-1.79)$ & $0.92(0.73-1.16)$ \\
\hline \multicolumn{5}{|l|}{ Educational level } \\
\hline No education ${ }^{\dagger}$ & 1.00 & 1.00 & 1.00 & 1.00 \\
\hline Primary & $2.8 \mathrm{I}(1.84-4.29)^{* *}$ & $1.97(1.56-2.49)^{* *}$ & $\mathrm{I} .88(\mathrm{I} .47-2.40)^{* * *}$ & $1.50(1.15-1.96)^{* *}$ \\
\hline \multirow{2}{*}{ Post primary } & $8.21(5.17$ & $6.03(4.42-8.23)^{* *}$ & $2.86(2.11-3.87)^{* *}$ & $2.13(1.58-2.88)^{* *}$ \\
\hline & $|3.0|)^{* *}$ & & & \\
\hline \multicolumn{5}{|l|}{ Age } \\
\hline $15-19^{+}$ & 1.00 & 1.00 & 1.00 & 1.00 \\
\hline \multirow[t]{2}{*}{$20-29$} & $\mathrm{I} .13(0.70-\mathrm{I} .83)$ & $\mathrm{I} .13(0.86-1.49)$ & $1.56 \quad(1.17$ & $1.18(0.86-1.63)$ \\
\hline & & & $2.08)^{* *}$ & \\
\hline $30-39$ & $\mid .5 \mathrm{I}(0.89-2.56)$ & $0.94(0.67-1.32)$ & $\mathrm{I} .6 \mathrm{I}(\mathrm{I} . \mathrm{|} 4-2.27)^{* * *}$ & $1.35(0.94-1.94)$ \\
\hline $40-49$ & $0.97(0.52-1.82)$ & $0.59(0.38-0.91)^{*}$ & $\mathrm{I} .34(0.85-\mathrm{I} .8 \mathrm{I})$ & $0.79(0.54-1.16)$ \\
\hline \multicolumn{5}{|l|}{ Children Alive } \\
\hline None $^{+}$ & 1.00 & 1.00 & 1.00 & 1.00 \\
\hline \multirow[t]{2}{*}{$1-2$} & $1.49(1.00-2.21)^{*}$ & $1.70(1.21-2.4 \mid)^{* *}$ & $\mathrm{I} .57 \quad(1.14$ & $2.75(1.93-3.91)^{* * *}$ \\
\hline & & & $2.16)^{* *}$ & \\
\hline $3-4$ & $2.44(1.65-3.60)^{* *}$ & $2.96(2.07-4.22)^{* *}$ & $2.34(1.65-3.31)^{* *}$ & $3.81(2.67-5.42)^{* *}$ \\
\hline 5 and above & $4.70(2.96-7.48)^{* *}$ & $4.75(3.29-6.86)^{* *}$ & $2.46(1.69-3.58)^{* *}$ & $4.82(3.38-7.09)$ *** \\
\hline \multicolumn{5}{|l|}{ Residence } \\
\hline Urban ${ }^{\dagger}$ & 1.00 & 1.00 & 1.00 & 1.00 \\
\hline Rural & $0.27(0.21-0.35)^{* *}$ & $0.43(0.33-0.55)^{* *}$ & $0.7 I(0.54-0.93)^{*}$ & $0.8 \mathrm{I}(0.66-0.99)^{*}$ \\
\hline \multicolumn{5}{|l|}{ Marital status } \\
\hline Single $^{+}$ & 1.00 & 1.00 & 1.00 & 1.00 \\
\hline Married & $0.37(0.24-0.55)^{* *}$ & $0.38(0.27-0.54)^{* *}$ & $0.55(0.4 I-0.75)^{* *}$ & $0.62(0.44-0.89)^{* *}$ \\
\hline Cohabiting & $0.43(0.26-0.72)^{* *}$ & $0.42(0.29-0.62)^{* *}$ & $0.57(0.39-0.83)^{* *}$ & $0.58(0.4 \mathrm{I}-0.82)^{* *}$ \\
\hline Separated/Widowed & $0.70(0.39-1.28)$ & $0.44(0.29-0.67)^{* *}$ & $0.86(0.60-1.24)$ & $0.70(0.44-\mathrm{I} . \mathrm{II})$ \\
\hline \multicolumn{5}{|l|}{ Wealth quintile } \\
\hline Lowest $^{\dagger}$ & . & . & 1.00 & 1.00 \\
\hline Second & . & . & $1.49(1.03-2.17)^{*}$ & $1.58(1.20-2.09)^{* *}$ \\
\hline Middle & . & . & $1.46(1.02-2.08)^{*}$ & $1.73(\mathrm{I} .3 \mathrm{I}-2.28)^{* *}$ \\
\hline Fourth & . & . & $2.14(1.53-3.01)^{* *}$ & $2.34(1.74-3.14)^{* *}$ \\
\hline Highest & . & . & $3.42(2.29-5.12)^{* * *}$ & $2.87(2.07-3.97)^{* *}$ \\
\hline \multicolumn{5}{|l|}{ Work status } \\
\hline Not working ${ }^{\dagger}$ & 1.00 & 1.00 & 1.00 & 1.00 \\
\hline Working & $\mathrm{I} .07(0.79-\mathrm{I} .46)$ & $1.16(0.94-1.43)$ & $\mathrm{I} .07(0.88-\mathrm{I} .30)$ & I.I4(0.96- I.36) \\
\hline \multicolumn{5}{|l|}{ Region } \\
\hline Central $^{\dagger}$ & 1.00 & 1.00 & 1.00 & 1.00 \\
\hline Eastern & $0.55(0.38-0.79)^{* *}$ & $0.39(0.30-0.5 \mathrm{I})^{* *}$ & $0.93(0.72-1.21)$ & $\mathrm{I} .02(0.82-\mathrm{I} .27)$ \\
\hline Western & $0.70(0.48-1.01)$ & $0.52(0.38-0.7 I)^{* *}$ & $0.87(0.67-1.13)$ & $0.97(0.78-1.94)$ \\
\hline Northern & $0.33(0.19-0.56)^{* *}$ & $0.68(0.48-0.96)^{*}$ & $0.56(0.42-0.76)^{* *}$ & $0.90(0.68-1.19)$ \\
\hline
\end{tabular}

Note: Estimates were obtained using logistic regression; where, ${ }^{* *} p<0.01$, ${ }^{*} p<0.05$

$\dagger$ Represents reference category

Results in Table 4 reveal four predictors of modern contraceptive use among women across the study period. The predictors are educational level, marital status, number of children alive and residence. These findings can be summarized as 1017 follows: First, women with primary and postprimary education had increased odds of modern contraceptive use compared to those with no education across the study period $(p<0.01)$. Worth noting is that the odds of modern contraceptive use were higher among women with post-primary http://aps.journals.ac.za 
education when compared to the estimates among women with primary education. Further, a steady reduction in the odds of modern contraceptive use among women with primary and post-primary education is noted in the recent past. For example, the odds of modern contraceptive use among women with post-secondary education reduced from 8.21 in 1995 to 6.03 in 2000/200I, 2.86 in 2006 and to 2.13 in 2011. A similar trend is noted among women with primary education.

Second, rural residents had reduced odds of modern contraceptive use compared to their urban counterparts across the study period $(\mathrm{p}<0.0 \mathrm{l})$. The odds were $73 \%$ lower in 1995 (OR $=0.27)$, $57 \%$ in 2000/200I (OR = 0.43), 29\% in 2006 (OR $=0.7 \mathrm{I})$ and $19 \%$ in $20 \mathrm{II}(\mathrm{OR}=0.8 \mathrm{I})$. This evidence shows a downward trend in the influence of rural-urban variations in residence over the study period.

Thirdly, increased odds of modern contraceptive use were noted among women with a higher number of children alive compared to those with no children across the study period $(p<0.01)$. Particularly, the odds are highest - across the study period- among women with at-least five children, followed by those with 3-4 children and lowest among women with at most two children.

Fourthly, women who were married and those cohabiting were less likely to use modern contraceptives compared to the single/never married across the study period ( $p<0.01$ ). Particularly, the odds of modern contraceptive use among the married women were $63 \%(\mathrm{OR}=0.37)$, $62 \%(O R=0.38), 45 \%(O R=0.55)$ and $38 \%(O R$ $=0.62)$ lower in 1995, 2000/200I, 2006 and 20II, respectively. A similar trend is noted among women who were cohabiting in the study period.

Worth noting is the wealth index which could as well be argued as predictors of modern contraceptive use across the study period although no data on the variable was available in 1995 and 2000/200I. Results based on 2006 and 2011 show that women in the second, third, fourth and highest wealth quartiles had increased odds of modern contraceptive use compared to their counterparts in the lowest quartile. There were no major variations in odds of modern contraceptive use in 2006 and 2011 . With the exception of 2011, the geographical regional variation was a predictor of modern contraceptive use. In other words, the odds of modern contraceptive use were lower among women in the Eastern, Western and Northern compared to their counterparts in the Central. http://aps.journals.ac.za
Particularly, the northern region had $67 \%$ reduced odds of modern contraceptive use in 1995, 32\% in $2000 / 2001$ and $44 \%$ in 2006. However, no significant variation in modern contraceptive use was noted in the region during $20 \mathrm{II}$ when compared to the central $(p>0.05)$.

\section{Discussion}

The predictors of modern contraceptive use across the study period are education level, age, number of surviving children, residence and wealth status of women. Particularly, increased odds of modern contraceptive use across the study period were noted among women with primary and post-primary education, those in urban areas, women in the higher wealth quartiles and those with a higher number of surviving children. However, varying odds of modern contraceptive use noted in the results demonstrate differentials in the net-impact of these factors in the various study periods. For example, women in the rural areas had $73 \%, 57 \%$, $29 \%$ and $19 \%$ reduced odds of modern contraceptive use in the years 1995, 2000/200I, 2006 and 201I, respectively. The reduced odds of modern contraceptive use in the rural areas has been attributed mainly to shortfalls with regards to accessibility (e.g., Nguyen et al., 2002; UBOS and Macro International, 2006; ) and affordability (Bailey, et al., 1994; Lewis, 1986; Jonawitz, 2010; Wangei, et al., 200I) of FP services. Although women with primary and post-primary education were more likely to use modern contraceptives, a downward trend was noted in the odds of the latter group from 8.21 in 1995, 6.03 in 2000, 2.86 in 2006 and 2.13 in $201 \mathrm{l}$. A similar trend is noted among women with primary education when compared to those with no education. It is highly probable that the odds modern contraceptive use among women with postprimary education and those in rural areas will continue to reduce in the near future. It would therefore be no surprise that the factors will not significantly predict modern contraceptive use in the near future. Nevertheless, the trend in the odds of modern contraceptive use across the study period points to a positive impact of interventions geared towards reducing rural-urban variation in access to and utilization of FP services in the country.

Contrary to a downward trend in the odds of modern contraceptive use among women with postprimary education, the trend was otherwise with regards to the coverage of women with the education level in the study period. This evidence suggests that utilization of modern contraceptive 
methods does not necessarily increase with education level of women. All the same, a higher contraceptive use among educated women (Ayad, Ocho and Wilkinson, 1991; Hagen, et al., 1999; Kravdal, 2002; Lutalo, et al., 2000; Rob et al., 2007; Utomo et al., 1983; UBOS and Macro International, 2006) affirms the relevance of education in matters concerning FP utilization. Thus, the argument that Universal Primary (UPE) and Secondary Education (USE) work towards enhancing modern contraceptive use in the country is highly supported.

There were no major variations in the odds of modern contraceptive use by number of surviving children across the study periods. These findings suggest that the variable would be a more reliable predictor of modern contraceptive use in the near future when compared to education level and residence that had a downward trend with regards to the odds of modern contraceptive use. Likewise, no major variations were noted in the odds of modern contraceptive use by socio-economic status of women, investigated in the study on the basis of the wealth index. Although data on the wealth index was not available in 1995 and $2000 / 200$ I, it is highly probable that similar conclusions would be reached in these periods. Based on the findings, the argument of modern contraceptive use being twice as high among the wealthiest women when compared to the poorest (Family Health Initiative, 2010) is highly supported. The low utilization of contraceptives among the poor women is attributed - among other factors - to costs associated with the services and related aspects (Gharoro, 1999; Wangei, et al., 200I).

Worth noting is the reduced odds of modern contraceptive use in the northern region in the period 1995, 2000/200I and $2006(p<0.05)$ when compared to the central region. The period 19952006 represents a stage of political instability in the northern region of the country. However, a nonsignificant difference in modern contraceptive use in the region when compared to the central region in $201 \mathrm{I}$ implies that interventions by government and other development agencies operating in the region have yielded a positive impact with regards to enhancing access to and utilization of modern contraceptives.

In conclusion, the determinants of modern contraceptive use across the study period demonstrate aspects to consider in enhancing FP utilization in the near future. These comprise stepping-up measures in enhancing: (i) literacy levels of woman particularly, (ii) accessibility and 1019 affordability of the services, and (iii) awareness campaigns on FP use targeting both men and women. However, the conclusion and recommendations may not be applied entirely to women across countries although the findings are indicative of the pattern and trend of modern contraceptive use in many developing countries.

\section{Acknowledgement}

The authors would like to thank the Uganda Bureau of Statistics (UBOS) and Macro International for providing the dataset. The authors acknowledge support to Allen Kabagenyi from Training Health Researchers into Vocational Excellence in East Africa (THRiVE), grant number 087540 funded by the Well come Trust. The contents are solely the responsibility of the authors and do not necessarily represent the official views of the supporting offices.

\section{Authors' contribution}

This work is a product of the intellectual environment of the whole team. All members have contributed - in various capacities - to its conceptualization and design, data analysis and interpretation, drafting of the article as well as approval of the version to be published.

\section{References}

Agyei, W.K. and Migadde, M., 1995. Demographic and socio-cultural factors influencing contraceptive use in Uganda. Journal of Biosocial Science, 27(I), pp.47-60.

Agyei, W.K.A. and Epema, E., 1990. Adolescent Fertility in Kampala. Knowledge, perception and practice in Biology and Society, 7(4), pp. 203 - 214

Andersen, R., 1995. Revisiting the behavioral model and access to medical care: does it matter? J Health Soc Behav, 36 (I), pp. I-10

Bailey, W., Wynter, H.H., Lee, A., Oliver, P. and lackson, J., 1994. The effect of user fees on the utilization of family planning services. A clinical study. West Indian Med J., 43(2), pp.43-5.

Barnett, B. and Stein, J., 200I. Women's voices, women's lives: The impact of family planning. North Carolina, The women's studies project.

Bongaart, J. and Potter, R.P., 1983. Fertility, Biology and Behavior: An analysis of the proximate determinants. New York: Academic press.

Cleland, R., Bernstein, S., Faundes, A. and Glasier, A., 2006. Family Planning: the unfinished agenda. Lancet, 368(9549), pp.1810 - 1827.

Creanga, A.A., Gillespie, D., Karklins, S. and Tsu, A.O., 20II. Low use of contraception among poor women in Africa: an equity issue. Bulletin of 
the World Health Organization, 89, pp.258-266. doi: 10.247I/BLT.10.083329

Dawud, A., 2008. Contraceptive practices and relative factors: female in predominantly rural Muslims of Northern India. The Journal of world health and societal politics, 5(I), pp. $5-6$.

DeRose, L.F. and Ezeh, C., 20I0. Decision - Making Patterns and Contraceptive Use: Evidence from Uganda. Population Research and Policy review, 29(3), pp.423 - 439.

Family Health Initiative. 2010. Expanding Contraceptive Use in Urban Uttar Pradesh: Family Planning: Effect of Data Driven Strategies. Policy Brief. Available at <www.uhi-india.org/> [Accessed November 2013]

Hagen, C.A., Fikree, F.F., Sherali, Afroze. Hoodbhoy, et al., 1999. Fertility and Family Planning Trends in Karachi, Pakistan. International Family Planning Perspective, 25 (I), pp. 10 - 33

Hladik, W., Stover, J., Esiru, G., Harper, M. and Tappero, J., 2009. The Contribution of Family Planning towards the Prevention of Vertical HIV Transmission in Uganda. PLoS ONE, 4(I I): e769I. doi: 10.1371/journal.pone.000769 I

Hosmer, D.W. and Lemeshow, S., 1980. Goodness of - fit test for the multiple logistic regression models. Communication institute: Theory and methods, 9(10), pp.1043 - 1069

ICF International, 20I2. MEASURE DHS STAT compiler. Available at: <http://www.statcompiler.com>. [Accessed 19 September 2012].

Kravdal, Øystein, 2000. A search for aggregate-Level effects of education on fertility, using data from Zimbabwe. Demographic Research 3(3): DOI: 10.4054/DemRes.2000.3.3. Available at $<$ http://www.demographic-

research.org/volumes/vol3/3/3-3.pdf $>$ [Accessed October 2013]

Lanre, O., 20II. Factors influencing the choice of family planning among couples in Southwest Nigeria. International Journal of medicine and medical science, 3(I), pp.227-232.

Gupta, N. and Leite, L.C, 1999. Adolescent Fertility Behavior: Trends and Determinants in Northeastern Brazil. International Family Planning Perspectives, 25(3). Available through: Guttmacher Institute < http://www.guttmacher.org/pubs/journals/25I 25 99.html >
Lewis, M.A., 1986. Do contraceptive prices affect demand? Studies in Family Planning, 17(3), pp. I26-35.

Lutalo, T., Kidugavu, M., Wawer, M.J., Serwadda, D., Zabin, L.S. and Gray, R.H., 2000. Trends and determinants of contraceptive use in Rakai District, Uganda, 1995-98. Studies in Family Planning, 3I (3), pp.2I7-27.

McGinn, T., Austin, J., Anfinson, K., Amsalu, R., Casey, S. E., Fadulalmula, S. I., Langston, A., et al., 20I I. Family planning in conflict: results of cross-sectional baseline surveys in three African countries. Conflict and health, 5:11. doi: I0.1186/I752-I505-5-II.

Ministry of Health, 2005. National Family Planning Advocacy Strategy, 2005-2010. Health Promotion and Education Division, Reproductive Health Division. Kampala: Ministry of Health.

Najafi, F., Rahman, H.A., Hanafiah, M., Momterz, Y.A., and Ahmad, Z., 2012. Emergency Contraception: knowledge, attitudes and practices among married Malay women staff at a public university of Malaysia. Southeast Asian J Trop Med Public Health, 43(6), pp.I5I 2 - 20

Ntozi, J.P.M and Kabera, J.B., 199I. Family Planning in Rural Uganda: A case study of Ankole. Studies in Family Planning, 22(2), pp. II 6 - 123.

Obung, W., Cross, A. and Njogu, W., 1991. Policy implications of the DHS findings for Kenya. DHS World Conference. August 5 - 7, 1991. Washington D.C

Population Secretariat, 1996. Situation Analysis and National Plan of Action: Gender, Special groups, Socio-cultural and legal issues Sector. Uganda: Ministry of Finance and Economic Planning

Rob, S., Baschieri, A., Steve, C., Monique, H. and Nyovani, M., 2007. Contextual influences on modern contraceptive use in Sub - Saharan Africa. American Journal of Public health, 97(7), pp. 1233 - 1240.

Rutenburg, N., Ayad, M., Ocho, L. and Wilkinson, T., 1991. Knowledge and use of contraception. Demographic and health science surveys studies. Comparative studies No.6. Columbia, Maryland: Institute for Resource Development. Available at <http://www.ru.nl/publish/pages/5 16298/nice_I 2109.pdf $>$

Sembajwe, I. and Makatjane, T., 1987. Fertility and Mortality Survey: Information on Females Aged 15 to 59 Years, Working Papers in Demography No. 12, Lesotho: Demography Unit Department of Statistics National University of Lesotho. 
Thomas, L., Medi, K., Maria, J., Laurie, S., David, S. and Ronald, H., 2000. Trend and Determinants of Contraceptive use in Rakai District, Uganda: 195 - 1998. Studies in Family Planning, 3I(3), pp. $217-227$.

Uganda Bureau of Statistics and ICF International, 2012. Uganda Demographic and Health Survey 2011. Available through: Measure DHS < http://www.measuredhs.com/Publications/Public ation-Search.cfm?type $=5>$ [Accessed March 2013]

Uganda Bureau of Statistics and Macro International, 1995. Uganda Demographic and Health Survey 1995 report. Available through: Uganda Bureau of Statistics

$<$

http://www.ubos.org/onlinefiles/uploads/ubos/pdf \%20documents/Uganda\%20DHS\%201995\%20

Final\%20Report.pdf $>$ [Accessed October 20I3]

Uganda Bureau of Statistics and Macro International, 2000. Uganda Demographic and Health Survey 2000 Report. Available through: Uganda Bureau of Statistics < http://www.ubos.org/onlinefiles/uploads/ubos/pdf \%20documents/Uganda\%20DHS\%201995\%20 Final\%20Report.pdf $>$ [Accessed October 20I3] Uganda Bureau of Statistics and Macro International, 2006. Uganda Demographic and Health Survey 2006. Available through: Uganda Bureau of Statistics http://www.ubos.org/onlinefiles/uploads/ubos/pdf \%20documents/Uganda\%20DHS\%202006\%20 Key\%20Findings.pdf $>$ [Accessed October 20I3]
United Nations Population Fund, 2012. Reproductive Health. Ensuring that every pregnancy is wanted. Available at $<$ http://www.unfpa.org/rh/planning.htm> [Accessed January 20I3]

United Nations Population Fund, 199I. The State of World Population, London: Nuffield Press.

Utomo, B., Alimoeso, S. and Park, C.B., 1983. Factors affecting the use and non use of contraception. Majalah Demografi Indones, 10(20), pp.19-48. Available at <http://www.ncbi.nlm.nih.gov/sites/entrez>

Wener, T., 1993. Use of Birth Control by the Rural Population, USA: Wiley and Sons.

World Health Organization, 2008. Medical Eligibility Criteria for Contraceptive Use. 2008 Update. Available at http://www.whqlibdoc.who.int/hq/2008/WHO R HR 08.19 eng.pdf $>$ [Accessed November 2013]

World Health Organization, 2012. MDG5: Improve maternal health. Available at $<$ http://www.who.int/topic/millenium development goals/ maternal health/en/index.html > [Accessed January 20I3]

World Health Organization, 2013. Family Planning. Fact Sheets $\mathrm{N}^{\circ} 35 \mathrm{I}$. Available at < http://www.who.int/mediacentre/factsheets/fs35 I/en/> [Accessed November 2013] 